\title{
Cholera like expression of Escherichia coli: An outbreak investigation from Central India
}

\section{Ankur Joshi, Saket Kale}

Department of Community Medicine, Gandhi Medical College, Bhopal, Madhya Pradesh, India

Address for the Correspondence: Dr. Ankur Joshi, Department of Community Medicine, Gandhi Medical College, Bhopal - 462 001, Madhya Pradesh, India. E-mail: drankurjoshi7@gmail.com

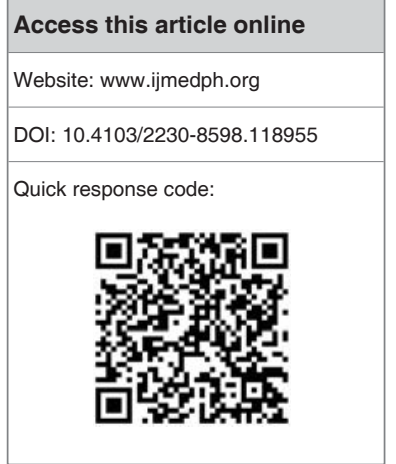

Background: This paper investigates a swift gastrointestinal outbreak in central India and further explores environmental, agent, and host interactions culminating into outbreak. Materials and Methods: Epidemic investigation was launched as per the standard protocol laid by Center for Disease Control to capture the clinico-microbiological pattern of disease. Descriptive and observational epidemiological analysis was performed. Results: This cholera like watery diarrheal episode presented along with vomiting and abdominal cramps had an attack rate of $45.11 \%$. The mean duration of illness was $61 \mathrm{~h}$ with a predilection to pediatric age group. Clinico-microbiological picture probed the enterotoxicogenic Escherichia coli contaminated well-water as a source for the outbreak initiated by geo-environmental stimulation. Conclusion: The findings endorse the need of serviceable environmental sanitation strategies in order to prevent the disease transmission through water.

Key words: Cholera, enterotoxicogenic Escherichia coli, rainfall, watery diarrhea

\section{INTRODUCTION}

India has attained a noticeable progress in sustainable access to improved water source and better sanitation in alignment with Millennium Development Goal. ${ }^{[1]}$ Despite the fact, diarrheal diseases continue to be the major threat to public health scenario of India as evident by 11.2 million cases and 1762 deaths in 2009. ${ }^{[2]}$ Moreover, National Institute for Cholera and Enteric Diseases have emerged with the same trends with 25,646,217 Disability Adjusted Life Year (DALY) for 2011 and 27,486,636 DALY projected for 2016 attributable to diarrheal disease. ${ }^{[3]}$ Enterotoxicogenic Escherichia coli (ETEC) is an under-recognized, but extremely important cause of diarrhea in the developing world and shares in absolute terms 280-400 million diarrheal episode in children under 5; 100 million episodes among 5-14 years and 400 million episodes among adults in India. ${ }^{[2]}$

There was a report of clustering of gastroenteritis cases in a tribal village situated in the hilly terrain of Madhya Pradesh, Central India. A two member team from Community Medicine Department visited the affected area on request of district health administration. Since the causative agent, source and mode of transmission for these gastroenteritis cases were not known until that time; the decision was taken by the team to launch an investigation for this gastrointestinal outbreak and ascertaining interaction between agent, host, and environment. This decision making was based on the decision matrix proposed by Goodman, which states that effective control measures cannot be implemented without knowing at least about the source and mode of transmission of the agent. ${ }^{[4]}$

\section{MATERIALS AND METHODS}

The steps taken for outbreak investigation by the team were based on guidelines developed by Center for Disease Control and Prevention, Atlanta. ${ }^{[4]}$ The first case of gastroenteritis was reported on $17^{\text {th }}$ July, 2012 with the peaking of cases $48-72$ h thereafter. We compared 83 observed cases with previous 3 years gastroenteritis cases during the same period in that area recorded in district surveillance unit in order to confirm the existence of epidemic. This observed frequency was in notable excess as compared to previous years. The next step was to create a working clinical case definition by defining the population at risk, visiting the patients and further calculating frequency distribution of clinical features. Suspected case was defined as the resident of the affected village who 
had passed loose, liquid or watery stools more than three times in a day after $16^{\text {th }}$ July 2012. Epidemiological case sheets/case interview forms were designed to collect information on demographic details, time of onset of disease, previous exposure, sign and symptoms of disease, duration of disease, drinking water and dietary sources, exposure to common vehicle, recent travel, community gathering history and history of personal contacts. Data collected were descriptively analyzed in terms of time (epidemic curve) place (spot map and clustering) and persons (distribution of cases and attack rate as per demographic structure) to identify common experience and to demarcate the group involved in this common experience. All outliers $\left(25^{\text {th }} / 26^{\text {th }}\right.$ July) were extensively interviewed to get an insight about sources. A plausible hypothesis was formulated on the basis of analysis and further evaluated on microbiological and ecological grounds.

\section{RESULTS}

Out of the 184 residents, 83 persons suffered from the outbreak (attack rate $=45.11 \%$ ). This outbreak affected both males (49 out of 110 total, attack rate $=44.54 \%$ ) and females (34 out of 74 , attack rate $=45.95 \%$ ) with no statistically significant sex preferences $\left(\chi^{2}=0.001 ; P=0.971 ; \mathrm{df}=1\right) .0-15$ years age group was most frequently affected group $(25 / 50$; attack rate $=50 \%)$ followed by reproductive age group (44/99; attack rate $=44.4 \%$ ) and geriatric age group $(8 / 19$; attack rate $=42.1 \%)$.

Frequency distribution of symptoms and attack rate according to sex and age groups has been shown in Table 1, which suggests profuse watery diarrhea, vomiting, and abdominal cramping in some cases were the major complaints. Rectal pain and blood in stools were reported by none. The mean duration of the illness was approximately $61 \mathrm{~h}$ (15-107 h; 95\% confidence interval).

On interviewing of four active/previous patients at the time of survey, sudden onset, and rapidity in progression of symptoms were mentioned by all.

On investigating on environmental aspects of the outbreak, fish was consumed by 44 cases at least once in last 7 days out of the 83 total affected cases while remaining 39 cases were strictly vegetarian. A retrospective cohort analysis was performed to detect the association of gastroenteritis with fish eating, which showed a statistically insignificant association among two variables $\left(\chi^{2}=0.211\right.$; $P=0.64 ; \mathrm{df}=1$ ) [Table 2]. No recent social gathering (mela, assemblies) were noted. There was a negative history of consuming food from a common source in last 15 days.

The only source of drinking water was the well, prior to the episodes of diarrhea. This well was open and had no parapet. The well-water was turbid and there were ditches containing water in the immediate vicinity. Villagers attributed the turbidity to the recent heavy rainfall in the area. As discussed with local authorities, well was not used to be chlorinated till outbreak.

There appeared to be no grouping of cases by either residence or worksite. The magnitude of the outbreak with reference to time course is being depicted by an epidemic curve [Figure 1].

This curve is characterized by sharp upward and downward slope, with the majority of cases occurring in a narrow time interval. This pattern mimics point source epidemic.

This environmental investigation raised the possibility of well-water as the source of infective organism. The probing factors behind this assumption were - ruling out the food as culprit statistically, unlined kaccha well as only drinking water source, turbidity of water

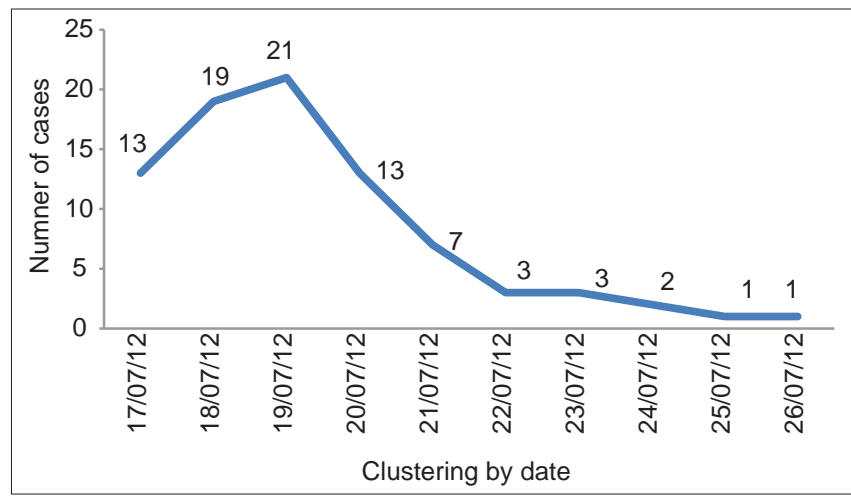

Figure 1: Epidemic curve of diarrhea cases suggesting point source outbreak

\begin{tabular}{|c|c|c|c|c|c|c|}
\hline \multirow[t]{2}{*}{ Sex } & \multirow[t]{2}{*}{ Age (years) } & \multicolumn{4}{|c|}{ Clinical features distribution } & \multirow[t]{2}{*}{ Attack rate (\%) } \\
\hline & & Loose stool & Vomiting & Abdominal cramps & Fever & \\
\hline \multirow[t]{5}{*}{ Male } & $0-15$ & 16 & 11 & 5 & 2 & $16 / 31(51.6)$ \\
\hline & $16-30$ & 14 & 9 & 1 & 1 & $14 / 31(45.2)$ \\
\hline & $31-45$ & 9 & 8 & 0 & 0 & 9/22 (40.9) \\
\hline & $46-60$ & 4 & 3 & 2 & 0 & $4 / 13(30.8)$ \\
\hline & Above 60 & 6 & 4 & 4 & 1 & $6 / 13(46.2)$ \\
\hline \multirow[t]{5}{*}{ Female } & $0-15$ & 9 & 6 & 4 & 1 & 9/19 (47.4) \\
\hline & $16-30$ & 11 & 10 & 3 & 1 & $11 / 25(44)$ \\
\hline & $31-45$ & 10 & 8 & 2 & 0 & $10 / 21(47.6)$ \\
\hline & $46-60$ & 2 & 1 & 1 & 0 & $2 / 3(66.7)$ \\
\hline & Above 60 & 2 & 1 & 0 & 0 & $2 / 6(33.3)$ \\
\hline Total & & 83 & 63 & 22 & 6 & $83 / 184(45.11)$ \\
\hline
\end{tabular}




\begin{tabular}{lccc}
\multicolumn{4}{l}{ Table 2: Distribution of fish eater and vegetarian } \\
cohorts as per disease outcome
\end{tabular}

$\mathrm{GE}=$ Gastroenteritis

with no purification practices in place and possible contamination from recent heavy rainfall. The median incubation period of the disease was estimated as 36-48 $\mathrm{h}$ by calculating the period between the rainfall on 16-1 $7^{\text {th }}$ July 2012 as exposure and outbreak peak on $19^{\text {th }}$ July 2012. Median Incubation period, clinical presentation, and duration of illness (61-107 h) narrowed the possible contamination of well-water by Vibrio species or E. coli or mixed infections.

Rectal swabs from new patients (not put on any anti-microbial agents) and sample from drinking water source (well) were inoculated in Bile Salt Agar, which showed "no growth." Simultaneously another subculture on Mac-Conkey's Agar resulted into the growth of bright pink colonies; reactive to Indole and Methyl-Red test. These microbiological findings indicated possible contamination of well-water by E. coli. Although due to non-availability of advance microbiological diagnostics, further subtyping of E. coli could not be performed (ETEC has no phenotypic characteristics to make it recognizable in a plate of E. coli) yet clinical/microbiological features and epidemiological evidences suggested the role of ETEC in outbreak.

\section{DISCUSSION}

E. coli belongs to family Enterobactriaceae, commonly found in the gut of human and other warm blooded animals. Although most of the strains are harmless, some may cause severe diarrhea through contaminated food or water. ETEC through its mucosal adherence, heat labile (LT) and heat stable (ST) toxins mediated fluid secretions, may cause cholera like illness. Predominated symptoms are watery diarrhea, nausea, and mild cramps. Fever, severe cramps, and blood in stools are usually absent. Illness develops 1-3 days after exposure and usually lasts 3-4 days. ${ }^{[5]}$

The confirmatory diagnosis of the ETEC relies in the detection of gene encoding HL and HS through PCR or DNA probe. Due to the non-availability of these sophisticated diagnostics, burden of illness and characteristic presentation, it is acceptable to make a diagnosis based on a patient's history and symptoms. ${ }^{[5,6]}$

Discussing on a demographic perspective this study did not detect any significant sex predilection. An Egyptian study found higher incidences in male. ${ }^{[7]}$ Similarly; another study conducted during the inter-epidemic period in north India observed 53\% incidences among male, but neither commented the sex difference on a statistical plane. ${ }^{[8]}$
The attack rate was higher among pediatric age group, but adults and elderly population also suffered from diarrheal episodes. Few other studies from developing countries also noted more incidences among children. ${ }^{[7,9]}$ The rational for vulnerability may attribute to both environment and immunological factors. Repeated exposure to E. coli antigen is a common phenomenon in sub-optimum hygienic condition. This frequent encounter might serve as a booster for developing immunity and hence making adults less susceptible to develop clinical disease then children, however with this immune-genetics, colonization characteristics, co-pathogen, and genetic diversities among individuals, which promote or halt the progression into diarrheal episode. ${ }^{[10,11]}$

In this study, vehicle for transmission was contaminated well-water. Another study from the rural south India also attributed well-water as a source for ETEC infection. ${ }^{[9]}$ Studies from China, ${ }^{[12]}$ Isreal, ${ }^{[13]}$ Thailand, ${ }^{[14]}$ and Bangladesh ${ }^{[15]}$ reported ETEC contaminated water respectively from bottle water, inadequate distribution system, water containers, and flood as source.

The suspected role of food (fish) as a source of microorganism was ruled out by a retrospective cohort analysis yet there are reported ETEC diarrheal cases by Sushi fishes and salads from USA ${ }^{[16]}$ and processed raw food from Brazil. ${ }^{[17]}$ Similarly ETEC strains were isolated from raw fish, vegetable, and meat product from an Ethiopian community. ${ }^{[18]}$ Either the immediate reservoir may be water or food, it has to be polluted by human or animal wastes (feces), which are the ultimate source of ETEC contamination. ${ }^{[19]}$

The clinical manifestation in this episode mimicked to cholera like illness. There are similar other reports (of cholera like symptoms, but no detection of Vibrio during culture) published from Northern India and other part of the globe. ${ }^{[20,21]}$ Historically recognized as "non-vibrio cholera," the etiological agents for these cholera like illnesses were unknown until 1968 when ETEC was isolated from a number of such patients. The secretary nature of diarrhea was further explained by isolation of HL and HS enterotoxin through rabbit ileal loop experimental model. ${ }^{[2]}$

Two more villages alleging reporting diarrheal cases in the same district were visited. The clinical presentation, attack rate, predominant drinking water source as well and other epidemiological parameters were identical with this village; but, there was no apparently geo-spatial and social connection among these villages. The only assumed commonality was the exposure to recent rainfall.

Several studies around the globe (India, Bangladesh, and Thailand) do report the up surging of ETEC gastroenteritis incidences after rainfall or a rise in cases in rain. This seasonal pattern is being attributed to the ETEC (in human feces) contaminated water leaching to ground water. ${ }^{[9,14,15]}$ A study on seasonality of ETEC diarrheal episode from Gambia argues that surface well-water remained contaminated throughout the year yet the magnitude of contamination increases by 100 times within few days of new rains because of washing off excreta into well. ${ }^{[23]}$ This might also serve as plausible justification for the outbreak in this region as well. 
Regardless of having some limitations on the resource like inability to perform subtyping for E. coli, ambiguity to remark on some patients put on empirical antimicrobial treatment during the commencement; this study has strength to link the events to a meaningful sequence which manifested into outbreak. In summary, it may be hypothesized that the outbreak was trigger by environmental changes, which facilitated the leaching and contamination of well-water through ETEC and subsequently sudden outbursts of Cholera like illness. This chain of transmission could be break by practicing the sanitation barrier or/and prevented by intervention as simple as chlorination, rote-boiling, and hand washing. This fact establishes the need of primed serviceable public health system to avert morbidity like infective diarrhea through promoting healthy practices and judiciously applying the preventative measures en mass.

\section{REFERENCES}

1. mdgs.un.org [home page on internet]. New York: Development Indicator Unit, Statistics Division, United Nations; 2003. Available from: http:// www.mdgs.un.org/unsd/mdg/Resources/Static/Products/Progress2012/ Snapshots/IND.pdf. [Updated on 2012 Dec; Cited on 2013 Jan 12].

2. Park K. Park's Textbook of Preventive and Social Medicine. $21^{\text {st }}$ ed. Jabalpur: Bhanot Publication; 2011.

3. National Commission of Macroeconomics and Health, Ministry of Health and Family Welfare, Government of India, National Institute of Cholera and Enteric Diseases. Estimation of the burden of diarrheal diseases in India. New Delhi (India): National Commission of Macroeconomics and Health; 2005.

4. U.S. Department of Health and Human Services, Centers for Disease Control and Prevention. Principles of Epidemiology in Public Health Practice: An Introduction to Applied Epidemiology and Biostatistics. $3^{\text {rd }}$ ed. Atlanta: CDC; 2011.

5. CDC.gov [homepage on internet]. Atlanta: Centre for Disease Control and Prevention, National Center for Emerging and Zoonotic Infectious Diseases, 2005. Available form: http://www.cdc.gov/nczved/divisions/ dfbmd/diseases/enterotoxigenic_ecoli. [Updated on 2012 July 19; Cited on 2012 Aug 16].

6. Mandell GL, Bennett JE, Dolin R, editors. Principle and Practices of Infectious Disease. $7^{\text {th }}$ ed. Philadelphia: Churchill Livingstone Elsevier; 2010.

7. Rao MR, Abu-Elyazeed R, Savarino SJ, Naficy AB, Wierzba TF, Abdel-Messih I, et al. High disease burden of diarrhea due to enterotoxigenic Escherichia coli among rural Egyptian infants and young children. J Clin Microbiol 2003;41:4862-4. Available from: http://www.ncbi. nlm.nih.gov/pmc/articles/PMC254374. [Cited on 2013 Feb 12].

8. Taneja N, Rao P, Rao DS, Singh M, Sharma M. Enterotoxigenic Escherichia coli causing cholerogenic syndrome during an interepidemic period of cholera in North India. Jpn J Infect Dis 2006;59:245-8.

9. Kang G, Ramakrishna BS, Daniel J, Mathan M, Mathan VI. Epidemiological and laboratory investigations of outbreaks of diarrhoea in rural South India: Implications for control of disease. Epidemiol Infect 2001;127:107-12. Available from: http://www.ncbi.nlm.nih.gov/pubmed/11565560. [Cited on 2012 Sep 23].

10. Qadri F, Svennerholm AM, Faruque AS, Sack RB. Enterotoxigenic
Escherichia coli in developing countries: Epidemiology, microbiology, clinical features, treatment, and prevention. Clin Microbiol Rev 2005;18:465-83.

11. Clemens J, Savarino S, Abu-Elyazeed R, Safwat M, Rao M, Wierzba T, et al. Development of pathogenicity-driven definitions of outcomes for a field trial of a killed oral vaccine against enterotoxigenic Escherichia coli in Egypt: Application of an evidence-based method. J Infect Dis 2004;189:2299-307.

12. Wang R, Cheng H, Zong J, Yu P, Fu W, Yang F, et al. An outbreak of acute gastroenteritis associated with contaminated bottled water in a university Jiangxi, China, 2012. West Pac Surveill Response J 2012;3:20-4.

13. Huerta M, Grotto I, Gdalevich M, Mimouni D, Gavrieli B, Yavzori M, et al. A waterborne outbreak of gastroenteritis in the Golan Heights due to enterotoxigenic Escherichia coli. Infection 2000;28:267-71.

14. Haque QM, Yoshimura H, Midorikawa $Y$, Nakamura S, Sugiyama A, Iwade $\mathrm{Y}$, et al. Epidemiological study on contamination of water and diarrheal diseases in a rural community in northeast Thailand. Environ Health Prev Med 1996;1:20-7.

15. Qadri F, Khan Al, Faruque AS, Begum YA, Chowdhury F, Nair GB, et al. Enterotoxigenic Escherichia coli and Vibrio cholerae diarrhea, Bangladesh, 2004. Emerg Infect Dis 2005;11:1104-7. Available from: http://www.wwwnc.cdc.gov/eid/article/11/7/pdfs/04-1266.pdf. [Cited on 2012 Nov 12].

16. Jain S, Chen L, Dechet A, Hertz AT, Brus DL, Hanley K, et al. An outbreak of enterotoxigenic Escherichia coli associated with sushi restaurants in Nevada, 2004. Clin Infect Dis 2008;47:1-7.

17. Reis MH, Vasconcelos JC, Trabulsi LR. Prevalence of enterotoxigenic Escherichia coli in some processed raw food from animal origin. Appl Environ Microbiol 1980;39:270-1.

18. Jiwa SF, Krovacek K, Wadström T. Enterotoxigenic bacteria in food and water from an Ethiopian community. Appl Environ Microbiol 1981;41:1010-9.

19. CDC.gov. Atlanta: Centre for Disease Control and Prevention, National Center for Immunization and Respiratory Diseases: Division of Bacterial Diseases, 2005. Available from: http://www.cdc.gov/ncidod/ dbmd/diseaseinfo/etec_g.htm. [Updated on 2012 Sep 28; Cited on 2013 Apr 16].

20. Finkelstein RA, Vasil ML, Jones JR, Anderson RA, Barnard T. Clinical cholera caused by enterotoxigenic Escherichia coli. J Clin Microbiol 1976;3:382-4. Available from: http://www.ncbi.nlm.nih.gov/pmc/articles/ PMC274305. [Cited on 2012 Dec 13].

21. Sack DA, McLaughlin JC, Sack RB, Orskov F, Orskov I. Enterotoxigenic Escherichia coli isolated from patients at a hospital in Dacca. J Infect Dis 1977;135:275-80. Available from: http://www.ncbi.nlm.nih.gov/ pubmed/320276. [Cited on 2012 Oct 30].

22. Sack RB. The discovery of cholera-like enterotoxins produced by Escherichia coli causing secretory diarrhoea in humans. Indian J Med Res 2011;133:171-80. Available from: http://www.ncbi.nlm.nih.gov/pmc/ articles/PMC3089048. [Cited on 2012 Oct 30].

23. Rowland MG. The Gambia and Bangladesh: The seasons and diarrhoea. Dialogue Diarrhoea 1986;26:3.

How to cite this article: Joshi A, Kale S. Cholera like expression of Escherichia coli: An outbreak investigation from Central India. Int J Med Public Health 2013;3:151-4.

Source of Support: Nil, Conflict of Interest: None declared. 